Supporting Information

\title{
Critical Roles of High- and Low-Frequency Optical Phonons in Photodynamics of Zero-Dimensional Perovskite-like $\left(\mathrm{C}_{6} \mathrm{H}_{22} \mathrm{~N}_{4} \mathrm{Cl}_{3}\right) \mathrm{SnCl}_{3}$ Crystals
}

Xiaoyu Liu, Wenhui Wu, Yumeng Zhang, Yuanyuan Li, Huaxin Wu, and Jiyang Fan*

School of Physics, Southeast University, Nanjing 211189, P.R. China

E-mail: jyfan@seu.edu.cn

Experimental Section. Materials. $\mathrm{SnCl}_{2} \cdot \mathrm{H}_{2} \mathrm{O}$ (stannous chloride dehydrate, Aladdin, 99.9\%), $\mathrm{HCl}$ (Hydrochloric acid, Linfeng, 38\%), $\mathrm{C}_{6} \mathrm{H}_{18} \mathrm{~N}_{4}$ (tris(2-aminoethyl)amine, Macklin, 98\%). All materials were used without purification. Synthesis of tris(2-aminoethyl)amine hydrochloride. In a typical synthesis, the excess hydrochloric acid was slowly added to $\mathrm{C}_{6} \mathrm{H}_{18} \mathrm{~N}_{4}$ at $0{ }^{\circ} \mathrm{C}$. The organic salts were obtained after removal of the solvent and then dried at $80{ }^{\circ} \mathrm{C}$ for $12 \mathrm{~h}$. Synthesis of $\left(\mathrm{C}_{6} \mathrm{H}_{22} \mathrm{~N}_{4} \mathrm{Cl}_{3}\right) \mathrm{SnCl}_{3}$ crystals. Tris(2-aminoethyl)amine hydrochloride and $\mathrm{SnCl}_{2} \cdot \mathrm{H}_{2} \mathrm{O}$ with molar ratio of $1: 1$ were dissolved in $5 \mathrm{~mL} \mathrm{HCl}$ at room temperature to form a clear solution. After the solution remained still for $5 \mathrm{~min}$, the transparent crystals appeared. Then the crystals grew larger and larger. Finally, the synthesized crystals were precipitated, washed with ethanol, and dried at $60^{\circ} \mathrm{C}$ overnight. The powder was obtained through ultrasonic pulverization of the bulk crystals in ethanol.

Characterization. Single-crystal X-ray diffraction data were collected from the X'Pert PRO MPD system equipped with the Mo K $\alpha$ radiation at $193 \mathrm{~K}$. The crystal structures were resolved and refined using the SHELX program. ${ }^{1}$ Powder X-ray diffraction (XRD) was performed using an X-ray powder diffractometer (Smartlab (3)). Reflectance spectra were recorded by using an UV-Vis spectrophotometer (HITACHI U-3900). Photoluminescence (PL) spectra, PL excitation (PLE) spectra, and time-resolved PL spectra were measured at room temperature by using a fluorolog3-TCSPC spectrofluorometer (HORIBA JOBIN YVON) with a Xe lamp and pulsed-laser diodes as the light sources. Temperature-dependent PL spectra were measured using an FLS1000 Photoluminescence Spectrometer with a Xe lamp as the light source. The samples were cooled to liquid helium temperature using an Oxford OptistatDN cryostat.

Simulations. The density function theory (DFT) calculations were performed by using the Vienna ab-initio simulation package (VASP) 5.4.4. ${ }^{2}$ the projected augmented wave (PAW) method was used to describe the interaction between the ionic core and valence electrons. ${ }^{3}$ The electronic structure and density of states (DOS) of $\left(\mathrm{C}_{6} \mathrm{H}_{22} \mathrm{~N}_{4} \mathrm{Cl}_{3}\right) \mathrm{SnCl}_{3}$ were calculated using the Perdew-Burke-Ernzerhof (PBE) exchange-correlation functional. ${ }^{4}$ The lattice constants were relaxed and the atomic positions were rearranged till the force on every atom was less than 0.01 meV/Angstrom for structural optimization. The kinetic energy cutoff of the 
plane-wave basis was $550 \mathrm{eV}$ and the Monkhorst-Pack k-mesh of $3 \times 3 \times 3$ was employed for lattice relaxations and static self-consistent field calculations. The optical excitation and emission energies were calculated using the hybrid PBE0 functional. ${ }^{5}$ Only one $\mathrm{k}$ point was used for the Brillouin zone integration for calculation of the excited state. The dynamical matrix obtained from VASP was used in Phonopy to obtain the phonon frequencies. Density functional perturbation theory was used to predict the phonon energies at a $2 \times 2 \times 2$ grid. The phonon band structures were then interpolated from this grid using the interatomic force constants.

Table S1. Crystal data and structure refinement for $\left(\mathrm{C}_{6} \mathrm{H}_{22} \mathrm{~N}_{4} \mathrm{Cl}_{3}\right) \mathrm{SnCl}_{3}$.

Compound

Empirical formula

Formula weight

Temperature

Wavelength

Crystal system

Space group

Unit cell dimensions

Volume

$\mathrm{Z}$

Density

Absorption coefficient

F (000)

Crystal size

Theta range for data collection

Index ranges

Reflections collected

Independent reflections

Completeness to theta $=52.983^{\circ}$

Refinement method

Data / restraints / parameters

Goodness-of-fit on $F^{2}$

Final R indices [I $>2$ sigma(I)]

$\mathrm{R}$ indices (all data)

Extinction coefficient

Largest diff. peak and hole
$\left(\mathrm{C}_{6} \mathrm{H}_{22} \mathrm{~N}_{4} \mathrm{Cl}_{3}\right) \mathrm{SnCl}_{3}$

C6 H22 Cl6 N4 Sn

$481.66 \mathrm{~g} \mathrm{~mol}^{-1}$

193(2) K

$1.34139 \AA$

Triclinic

$\mathrm{P}-1$

$a=9.5045(9) \AA \quad \alpha=96.461(3)^{\circ}$

$b=9.5244(10) \AA$

$\beta=115.248(2)^{\circ}$

$c=10.2154(10) \AA$

$\gamma=93.515(3)^{\circ}$

824.92(14) $\AA^{3}$

2

$1.939 \mathrm{~g} \mathrm{~cm}^{-3}$

$14.319 \mathrm{~mm}^{-1}$

476

$0.220 \times 0.190 \times 0.170 \mathrm{~mm}^{3}$

$6.317^{\circ}$ to $52.983^{\circ}$

$-11 \leq \mathrm{h} \leq 11,-11 \leq \mathrm{k} \leq 11,-12 \leq \mathrm{l} \leq 12$

7414

$2804[\mathrm{R}(\mathrm{int})=0.0573]$

$95.7 \%$

Full-matrix least-squares on $F^{2}$

2804/0/158

1.109

$\mathrm{R}_{1}=0.0715, w \mathrm{R}_{2}=0.1863$

$\mathrm{R}_{1}=0.0715, w \mathrm{R}_{2}=0.1865$

0.031(3)

2.612 and $-2.371 \mathrm{e}^{-3}$ 
Table S2. Bond lengths of $\left(\mathrm{C}_{6} \mathrm{H}_{22} \mathrm{~N}_{4} \mathrm{Cl}_{3}\right) \mathrm{SnCl}_{3}$ single crystal.

\begin{tabular}{|l|l|l|l|l|}
\hline & Cl1-Sn1 & Cl2-Sn1 & Cl3-Sn1 & Sn1-Sn2 \\
\hline Ground state & $2.56 \AA$ & $2.57 \AA$ & $2.62 \AA$ & $4.42 \AA$ \\
\hline Excited state & $2.57 \AA$ & $2.63 \AA$ & $2.51 \AA$ & $3.63 \AA$ \\
\hline
\end{tabular}

Table S3. Bond angles of $\left(\mathrm{C}_{6} \mathrm{H}_{22} \mathrm{~N}_{4} \mathrm{Cl}_{3}\right) \mathrm{SnCl}_{3}$ single crystal.

\begin{tabular}{|l|l|l|l|}
\hline & $\mathrm{Cl} 3-\mathrm{Sn} 1-\mathrm{Cl} 2$ & $\mathrm{Cl} 3-\mathrm{Sn} 1-\mathrm{Cl} 1$ & $\mathrm{Cl}-\mathrm{Sn} 1-\mathrm{Cl} 1$ \\
\hline Ground state & $93.35^{\circ}$ & $84.72^{\circ}$ & $91.61^{\circ}$ \\
\hline Excited state & $93.76^{\circ}$ & $83.85^{\circ}$ & $90.58^{\circ}$ \\
\hline
\end{tabular}
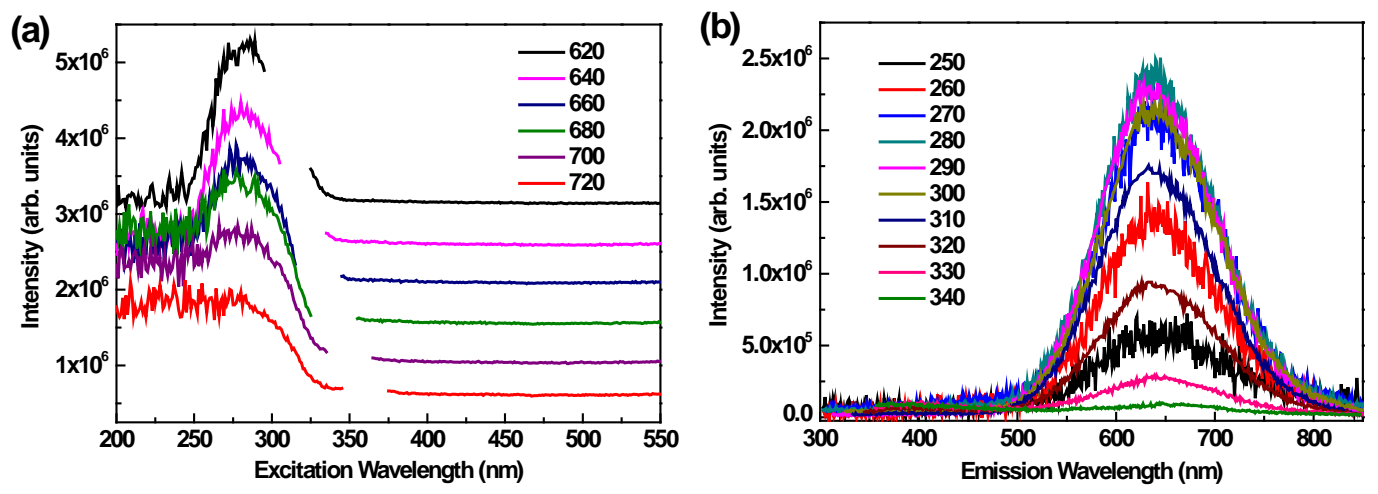

Figure S1. (a) PLE spectra and (b) PL spectra of $\left(\mathrm{C}_{6} \mathrm{H}_{22} \mathrm{~N}_{4} \mathrm{Cl}_{3}\right) \mathrm{SnCl}_{3}$ single crystal powder at denoted emission or excitation wavelengths.

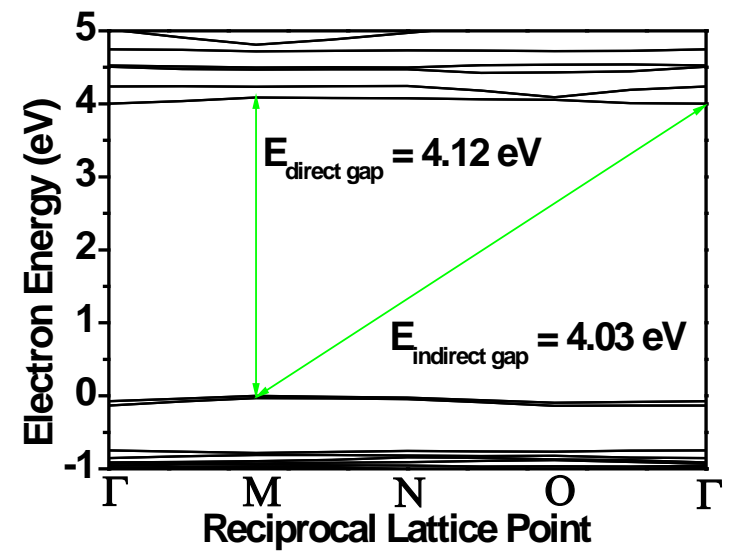

Figure S2. Electronic structure of $\left(\mathrm{C}_{6} \mathrm{H}_{22} \mathrm{~N}_{4} \mathrm{Cl}_{3}\right) \mathrm{SnCl}_{3}$ calculated using the DFT method including the spin-orbit coupling effect. 
Table S4. Electron distribution on the different ions in the supercell of the $\left(\mathrm{C}_{6} \mathrm{H}_{22} \mathrm{~N}_{4} \mathrm{Cl}_{3}\right) \mathrm{SnCl}_{3}$ single crystal corresponding to the ground state.

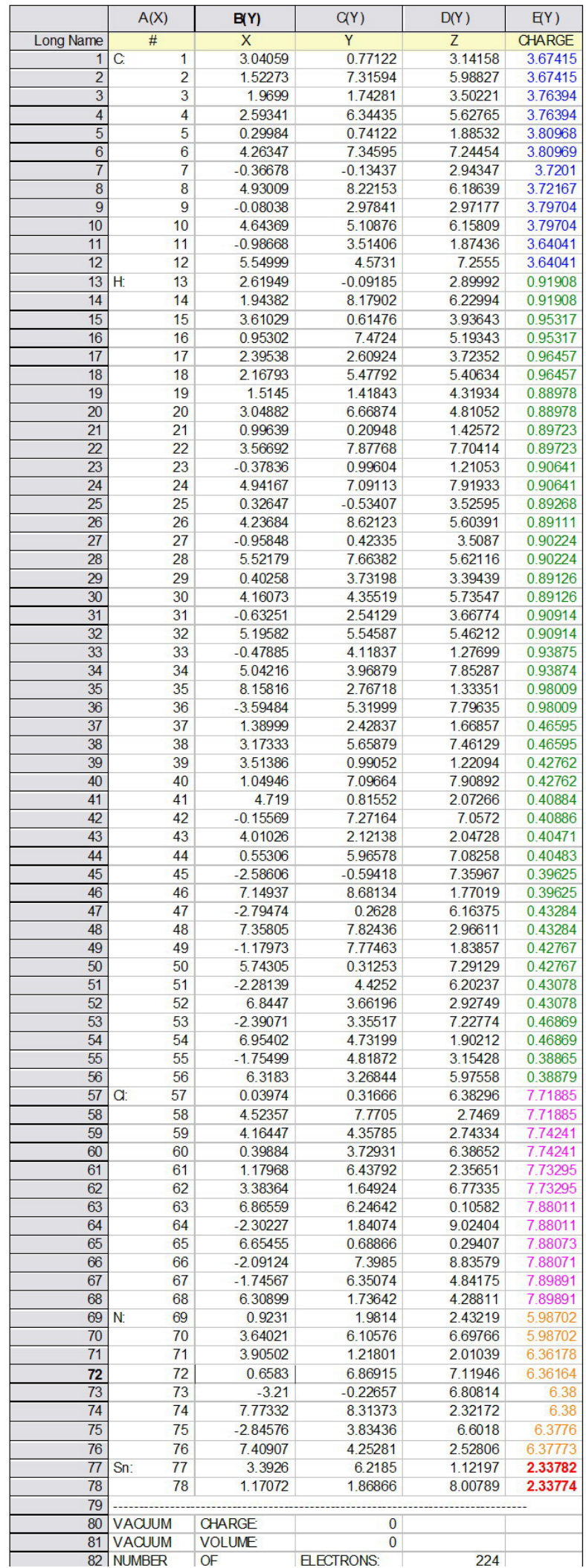




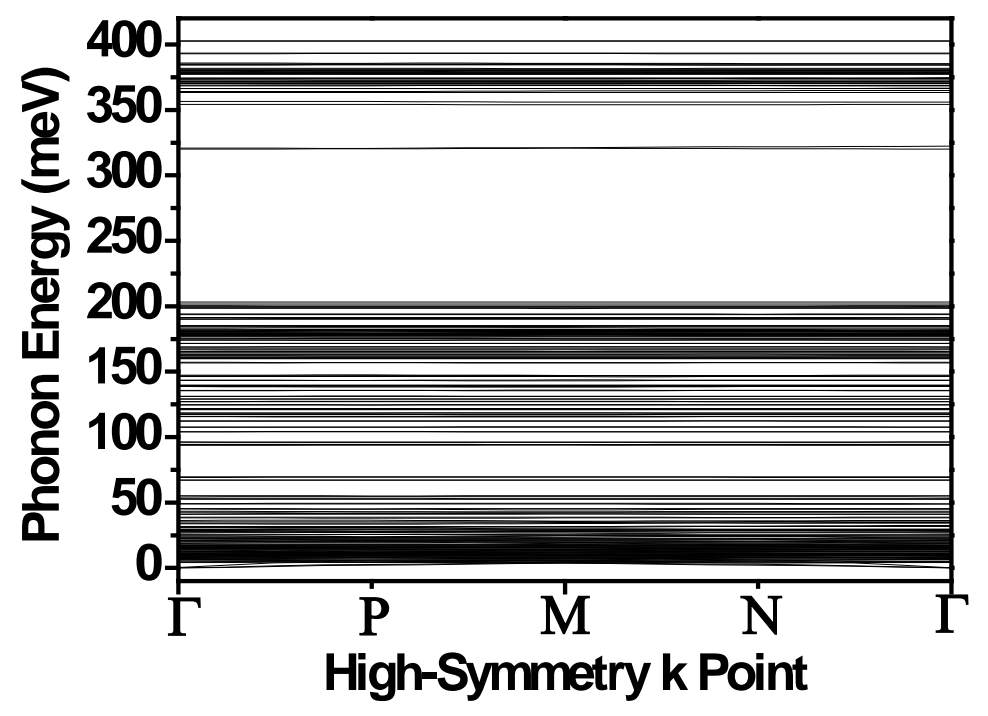

Figure S3. Phonon structure of $\left(\mathrm{C}_{6} \mathrm{H}_{22} \mathrm{~N}_{4} \mathrm{Cl}_{3}\right) \mathrm{SnCl}_{3}$ at high-symmetry k points in the first Brillouin zone.

\section{REFERENCES}

(1) Sheldrick, G. M. A Short History of SHELX. Acta Crystallogr. Sect. A 2008, A64, 112-122.

(2) Kresse, G.; Furthmüller, J. Efficiency of Ab-initio Total Energy Calculations for Metals and Semiconductors Using a Plane-Wave Basis Set. Comput. Mater. Sci. 1996, $6,15-50$.

(3) Blöchl, P. E. Projector Augmented-Wave Method. Phys. Rev. B 1994, 50, 17953-17979.

(4) Perdew, J. P.; Burke, K.; Ernzerhof, M. Generalized Gradient Approximation Made Simple. Phys. Rev. Lett. 1996, 77, 3865-3868.

(5) Perdew, J. P.; Emzerhof, M.; Burke, K. Rationale for Mixing Exact Exchange with Density Functional Approximations. J. Chem. Phys. 1996, 105, 9982-9985 